Hispania Sacra, LIX

120, julio-diciembre 2007, 595-612, ISSN: 0018-215-X

\title{
SU SANTIDAD EL PAPA PÍO IX, Y LA SEMANA SANTA ROMANA DE 1866, VISTO POR UN ILUSTRE VALENCIANO
}

\author{
POR \\ María Elena del Río Hijas XimeneZ \\ Académica Correspondiente de la Academia Valenciana de Genealogía y Heráldica. \\ Instituto de Historia de la Ciencia y Documentación López Piñero \\ Facultad de Medicina. CSIC-Universidad de Valencia
}

In memoriam de mi tío bisabuelo el Excmo. e Ilmo. Sr. Don Francisco de Paula Ximénez y Marco

\section{RESUMEN}

Francisco de Paula Ximénez y Marco hizo un viaje a Italia en 1866. Dejó una crónica inédita. Se publica el relato de su estancia en Roma, durante la semana santa de este año. La crónica de las celebraciones revela la fascinación que ejercía Pío IX sobre los peregrinos y nos informa sobre la organización de lo que quedaba de loa Estados Pontificios.

PALABRAS CLAVE: Pío IX, semana santa, limosnas de los católicos al Papa, Estados Pontificios.

\section{ABSTRACT}

Francisco de Paula Ximénez and Marco made a trip to Italy in 1866 . He left a chronicle unpublished. The story of his stay in Rome is published, during the Easter of this year. The chronicle of the celebrations reveals the fascination that exerted Pío IX on the travelling ones and it informs to us on the organization into which it was left of the Pontifical States.

KEY WORDS: Pío IX, Easter, Pontifical alms of the catholics for the Pope, Pontifical States.

Recibido/Received 10-05-2006

Aceptado/Accepted 16-10-2006 
Hace poco tiempo, ha llegado a mis manos este libro manuscrito, a través de mi prima Doña. Pilar Blanco Devis, viuda del Ilmo. Sr. Dr. Don Vicente Chuliá.

Es un ejemplar inédito, encuadernado, que es el dietario de mi tío bisabuelo el Excmo. e Ilmo. Sr. Don Francisco de Paula Ximénez y Marco, fechado en el año 1866, cuyo título es «Relación de mi viage hecho a ITALIA Y OTROS PUNTOS en el año 1866».

Este libro, consta de 314 páginas, manuscritas por ambas caras, con una caligrafía perfecta, que presenta un buen estado de conservación. En las contraportadas, tiene varios mapas de la época, donde iba señalando sus diferentes escalas, en ese largo viaje que duró más de dos meses. El libro, está dedicado a Su Santidad el Papa Pío IX y el comienzo de sus relatos, está encabezado, por la foto de Su Santidad. A medida que se van pasando las páginas, se ve el profundo cariño que el autor valenciano profesaba a este Pontífice, y de qué modo tan respetuoso va describiendo los diferentes momentos en que se encontró con él, y las circunstancias que ocurrían en Roma, en ese año de 1866.

Al final del libro, existe una relación de los kilómetros recorridos y los gastos que supuso su viaje a Italia. Nuestro querido viajero, recorrió 4.253 kilómetros, desde que sale de Valencia, el 2 de marzo de 1866 hasta el 3 de mayo en que regresa. Su aventura duró dos meses, y sus gastos fueron de 3.122 reales de vellón.

Es un aporte histórico, realizado por un ilustre valenciano, y que nos añade algunos detalles sobre la personalidad del Sumo Pontífice y del ambiente romano de aquellas fechas.

\section{EL AUTOR}

Nació Francisco de Paula Ximénez y Marco en Valencia, el 25 de diciembre de 1832. Era hijo de Don Juan Antonio Ximénez Pastor ${ }^{1}$ y de Doña Josefa Marco y Vidal. Sus familias paterna y materna pertenecían a la nobleza valenciana. El matrimonio de sus abuelos Juan Bautista Ximénez Pastor y Mariana Pastor Sanchís, celebrado en 1790, consta en el Libro de Desposorios de la nobleza valenciana, que se conserva en el Archivo Metropolitano de Valencia².

${ }^{1}$ Nacido en 1796. Escribano Real. Notario Público de su Majestad en España. Escribano de Número del Colegio de Valencia. Notario Mayor del Juzgado de la Real Orden Militar de Montesa y San Jorge de Alfama. Agente Diplomático. Oficial de la Embajada española en Bruselas. Condecorado con varias distinciones nacionales y extranjeras (Archivo del Reino de Valencia (cfr. Escritura matrimonial con Da. Josefa Marco y Vidal, Protocolo notarial $\mathrm{n}^{\circ}$ 9478, folio 205 vuelto-206) del escribano Don Salvador Sanchís). Cofrade del Real Sepulcro de San Bartolomé.

${ }^{2}$ Archivo Metropolitano. Libro de bautizos y matrimonios dela nobleza valenciana, año 1790, enlace Ximénez-Pastor.

Hispania Sacra, LIX

120, julio-diciembre 2007, 595-612, ISSN: 0018-215-X 
Su padre, era Escribano Real y Notario público de Su Majestad en toda España. Escribano de número del Colegio de Valencia, Notario mayor del Juzgado de la Real Orden Militar de Montesa y San Jorge de Alfama y Apoderado General del Conde de Rótova ${ }^{3}$.

Francisco de Paula, nace en Valencia el 25 de diciembre de 1832. Era Licenciado en Derecho. Terminados sus estudios y para poder ejercer, hace una instancia al Colegio Oficial de Abogados de Valencia, con fecha 6 de octubre de $1854^{4}$, para ser admitido como Abogado ejerciente en Valencia. Se le admite con fecha 21 de octubre.

El Papa Pío IX le nombró Notario Apostólico de la Curia Romana y Caballero de la Orden Pontificia de San Gregorio Magno (año 1867). Era también Caballero de la Real Orden de San Juan de Jerusalén y Secretario del Gran Priorato de Valencia y Caballero de la Cruz de Beneficencia. Gran Cruz de Isabel la Católica ${ }^{5}, \mathrm{Ca}-$ ballero de la Real Orden de Carlos III $^{6}$ y Concejal del Ayuntamiento de Valencia ${ }^{7}$.

Desde antes de 1860, era el Vocal Secretario de la Gran Asociación de Beneficencia domiciliaria de Nuestra Señora de los Desamparados, en Valencia. En ella, tuvo diferentes cargos: Vicesecretario, Secretario, Vocal de Honor, Vocal de Mérito, Presidente suplente y otros.

El 25 de noviembre de 1856, se casa con Carolina Torrent y Camilleri, con la que no tiene descendencia. Francisco de Paula, fallece en Valencia, el 19 de diciembre de 1877, a los 45 años de edad, debido a un infarto ${ }^{8}$. Cuando hizo el viaje a Italia, tenía 34 años. Su esposa fallece varios años después. Pío XI vivió hasta el 7 de febrero de 1878, Fue beatificado el 3 de septiembre de 2000 por el Papa Juan Pablo II.

\section{Su VIAJE A ITALiA}

En su libro, describe de modo muy pormenorizado, todo lo que le acontece día a día, los lugares por donde transcurre su viaje, donde pasa la noche, los monumentos que visita en cada lugar, añadiendo sus propios comentarios. Esto

\footnotetext{
${ }^{3}$ Archivo Histórico de Protocolos de Madrid, Protocolo 9505. folio 90 vuelto a 92 vuelto y Protocolo 14.638, con poder de él y ante el Cónsul de España en París, el 7 de noviembre de 1842. Sus Protocolos notariales, de 1829 a 1849. N 9716 a 9723, están en el Archivo del Reino de Valencia.

${ }^{4}$ Archivo Colegio de Abogados de Valencia, caja 36, expediente 10.

5 Con fecha 21 de mayo de 1871. Archivo Histórico Ministerio de Asuntos Exteriores, caja 256. exp. 5.

${ }^{6}$ Con fecha 31 de octubre de 1863. Archivo Histórico Ministerio de Asuntos Exteriores, caja 187.

${ }^{7}$ Las Provincias de 19 de diciembre de 1877.

${ }^{8}$ Registro civil de Valencia, Sección $3^{\mathrm{a}}$. Tomo 39-2. folio 7 y 8, nº 852). Testó en 1870, ante D. Eduardo Ponce. Enterrado el 20 de diciembre, en el Cementerio general de Valencia.
} 
hace que su libro de viajes, sea ameno, con un lenguaje muy asequible al lector y que nos hace comprender mejor todo lo que nos va describiendo.

El día 2 de marzo de 1866, a las 16,30 horas, sale de Valencia, y a partir de esta fecha, vamos recorriendo con él, los diferentes sitios por donde va pasando, describiendo como eran aquellos parajes en 1866. Utiliza ferrocarril, buque, y carruajes para poder recorrer tan largo trayecto. Cada día va desglosando sus diferentes visitas en cada ciudad y pueblo del norte de España, Francia e Italia. Llega a Roma el 10 de marzo, que era sábado.

\section{El AUTOR y PÍO IX}

La principal meta de nuestro autor era conocer personalmente al Papa Pío IX, y asistir a la mayoría de las ceremonias litúrgicas que presidiera dicho Pontífice y de modo secundario, conocer a fondo Roma.

Para conseguir su primer objetivo, traía cartas de recomendación de diferentes autoridades civiles y religiosas de España, para así obtener entradas y permisos necesarios.

Nos relata de modo muy riguroso en su dietario todo lo que sabe sobre la persona de Pío IX.

En cuanto terminó la Semana Santa, regresó a Valencia, utilizando los mismos transportes que a su ida y continuó su vida normal, siguió trabajando en la Asociación, en el Ayuntamiento...

El autor del libro manuscrito, tuvo dos hermanos: Desamparados Ximénez Marco y Juan José Ximénez Marco, militar de profesión, Fiscal Militar de Guerra de Valencia, Benemérito de la Patria. Desamparados colaboró mucho en la Gran Asociación de Beneficencia domiciliaria de Nuestra Señora de los Desamparados. Aparece en el archivo de esta Asociación como Señora protectora en el apartado de Señoras de la Nobleza Valenciana En la actualidad, en el año 2006, sigue funcionando la Gran Asociación de Beneficencia en Valencia.

Este relato narra estancia Don Francisco de Paula Ximénez y Marco en Roma, en la Roma del siglo XIX, en el Vaticano, con noticias sobre las ceremonias litúrgicas del época del este Papa Beato Pío IX. El autor muestras diferentes facetas de la personalidad de Pío IX, desde el 16 de junio de 1846, el 259 sucesor de Pedro.

\section{El TEXTO}

«Juan María Mastai Ferretti, nació en Sinigaglia el 13 de mayo de 1792; cinco años estudió con los escolapios y en 1809, recibió la primera tonsura, pasan- 
do a Roma a estudiar al lado de un tío suyo que era canónigo de la Basílica de San Pedro. Cuando era joven, estuvo enfermo, padeció bastantes ataques de epilepsia. Celebró su primera Misa en Roma, el día de Pascua de 1812 y fue nombrado coadjutor de un pequeño hospicio de niños pobres; a los 31 años, fue nombrado por Pío VII, auditor de la nunciatura de Chile, en donde aprendió el español, que todavía hablaba perfectamente. A este nombramiento se opuso su madre la condesa Mastai, escribiendo al cardenal secretario para que quedase el nombramiento sin efecto, lo cual sabido por Pío VII, dijo que -no temiera nada, pues su hijo volvería a Roma sano y salvo-, como así sucedió tres años después. Posteriormente fue elegido por el Papa, Prelado presidente del gran hospicio de San Miguel, en donde demostró sus grandes conocimientos para gobernar y prestó tan notables servicios, que el Papa León XII, le nombró Arzobispo de Espoletto y después fue trasladado en 1832 a la silla de Imola, con 40 años de edad.

Los grandes servicios que prestó a la Iglesia y al Estado en estas dos importantes diócesis, en medio de grandes revoluciones políticas, llamaron la atención de Su Santidad, el cual le proclamó cardenal el 14 de diciembre de 1840, con 48 años de edad, pero seguía al frente de su diócesis fuera de Roma. Al morir el Papa Gregorio XVI, de feliz memoria, acudió al Cónclave, llegando a Roma el 12 de junio de 1846; el día 15 reuniose el Cónclave de cardenales y el 16 fue elegido unánimemente Sumo Pontífice. Lo primero que hizo en el mismo día, fue escribir a sus hermanos una afectuosa carta dirigida a Sinigaglia en donde estaban, participándoles que [Dios se había complacido en levantarle de la nada a la dignidad más sublime del mundo], y además les dice: [si la ciudad desea hacer con este motivo algunas demostraciones públicas, que adopten las medidas necesarias, pero que su más vivo deseo era que la suma que para ello haya de destinarse, se emplee en algún objeto de utilidad general para sus habitantes, según la elección de las autoridades].

Pío IX, es de una estatura alta y robusto; grave sin afectación y tiene su persona un aire de distinción, una sonrisa y una gracia especial que impresiona y cautiva a cuantos le ven; en su trato descúbrese gran finura y bondad y una dulce serenidad y esperanza en Dios, a pesar de sus continuadas desgracias; cuyas distinguidas maneras han hecho decir a un príncipe real extranjero que le visitó por primera vez: [que parecía que había nacido rey]. En las funciones sagradas, su mirada resplandece con una belleza celestial; su voz es dulce y sonora, cantando con gran armonía el Prefacio, el Pater noster y otras oraciones.

Su caridad no tiene límites, pues, a pesar de los escasos recursos con que cuenta, yo no sé cómo se lo arregla para estar siempre haciendo costosas obras de caridad, pues mucho más de 300.000 duros anuales emplea en estas obras, que es más de la mitad de su dotación o lista civil, la cual asciende a 600.000 duros anuales. Acaba de remitir al arzobispo de Espoletto, que está hoy en po- 
der de Víctor Manuel, una fuerte suma para la conclusión de una iglesia que se está allí haciendo. A los nuevos hospicios para huérfanos del cólera, que se han fundado en Bolonia y Ferrara, les pasa una cantidad anual. Al obispo de Ptolemaida le ha costeado el viaje y dado una suma para los pobres de Cerdeña, a donde ha ido a confirmar, pues hace muchos años que no tienen prelado.

El Papa Pío IX, es un anciano, hermoso y majestuoso, de elevada estatura, de grave y dulce rostro, y que tiene una voz simpática y sonora, que halaga su especial mirada, y que es muy amable en su trato. Su traje ordinario de casa consiste en una sotana de lana blanca, solideo del mismo color y una ancha faja de seda blanca por la cintura, con la imagen de san Pedro bordada de seda de colores en las caídas, que terminan por unas bellotas de oro, el calzado es de terciopelo encarnado con una cruz de oro bordada cubre el empeine, que es la que besa todo el que se aproxima a su Persona, excepto los Cardenales, que besan su anillo del Pescador.

Es gran protector de las bellas artes, habiendo encargado muchos grandes cuadros a los principales pintores de Italia; muchas obras de escultura y fomentado costosas obras públicas en sus Estados; y en especial debidas a su magnificencia, siendo tan admirador de buenos artistas, que en más de una ocasión los ha reunido en el Vaticano y hasta les ha dado alguna comida. Siendo tan apasionado a las bellas artes, no es extraño que disfrute algún rato oyendo tocar el piano al célebre profesor Litz(sic), hoy fraile del monasterio del Monte Mario en Roma, a quien el Papa le ha dicho que [le había hecho gozar de antemano de la música celestial, y que, después que le había oído tocar, comprendía mejor los bellísimos coros de los ángeles].

Desde que al Papa se le ha despojado de la mejor mitad de sus Estados, ha recurrido a la caridad católica universal y son inmensas las sumas de dinero que ya tiene recibidas, pues pasan de 180 millones de reales lo recaudado para el dinero de san Pedro. La suscripción del Palacio Arzobispal de Valencia, asciende ya a más de 400.000 reales; en cuatro iglesias de París, el jueves y viernes Santo, se recogieron 250.000 reales, encontrándose en la bandeja de santo Tomás de Aquino, de dicha ciudad, un paquete de billetes de a 1.000 francos cada uno, con un letrero que decía: [para el Papa]. Y estos donativos, que son muy frecuentes, y se hacen bajo varias formas»?

A principios de esta Cuaresma, Pío IX dio audiencia a una madre que deseaba presentarle a su hijo que acababa de alistarse en la Legión extranjera, que consta de jóvenes católicos de todos los países del Orbe, teniendo jefes y soldados de grandes fortunas y de casas muy ilustres.

\footnotetext{
9 Francisco DE PaUla XiméneZ y Marco. 1886. Relación de mi viage hecho á Iitalia y otros puntos, en el año 1886. pp. 135-140.

Hispania Sacra, LIX

120, julio-diciembre 2007, 595-612, ISSN: 0018-215-X
} 


\section{ESTANCIA EN ROMA}

El domingo 11 de marzo, era cuarto domingo de Cuaresma, y ese día el Papa, asistía con todo el Sacro Colegio de Cardenales a la Capilla Sixtina del Vaticano a los oficios del día y a la bendición de la Rosa de Oro, por lo que nuestro viajero, acude a presenciarlos. Los particulares que asisten a las funciones religiosas en esta Capilla, han de ir de etiqueta, con traje negro y de frac y las señoras con traje largo negro y velo en la cabeza. El trono del Papa, estaba situado en el lado del Evangelio, y los asientos de los Cardenales, ocupaban el centro de la Capilla, formando una especie de anfiteatro y colocados por orden de categoría y antigüedad, comenzando por la derecha del Papa. Los Cardenales estaban ya en su sitio con ornamentos morados (era Cuaresma), esperando la llegada del Sumo Pontífice, que con su Corte, hace la entrada por la puerta del lado de la Epístola. En este día con motivo de la bendición de la Rosa de Oro, según la antigua costumbre, el Papa, se detiene en la sacristía de la Capilla Sixtina y un oficial de la Cámara Pontificia, puesto de rodillas, le presenta la dicha Rosa, que es un manojo de capullos con una gran Rosa en el centro, toda de oro, la cual regala Su Santidad a alguno de los Reyes o Príncipes reinantes de Europa que más se ha distinguido por su adhesión a la Santa Sede. Presentado este ramo que está colocado en un pequeño vaso de oro, un Cardenal toma el incensario y Su Santidad, inciensa la Rosa y recita una oración, colocando después en el centro de la flor, un poco de almizcle pulverizado y unas gotas de bálsamo, rociándola con agua bendita y bendiciéndola. Concluida esta ceremonia, es llevada por el mismo cardenal que la presentó delante de Su Santidad cuando éste sale de la capilla, colocándose en el altar, en donde permanece expuesta hasta la terminación de la Misa mayor, en cuyo acto se retira del Altar. Se cree que la antigüedad de esta ceremonia data del siglo XI.

Cuando termina la ceremonia, el Papa, con su corte, ocupa el Solio, da la bendición a todos los presentes y comienza la Misa Mayor, cantada por uno de los Cardenales.

Nos dice que: «para asistir a la Capilla Sixtina, el Papa lleva un roquete de encaje, una muceta encarnada de lana guarnecida de pieles blancas y una ancha estola bordada en oro». El Papa celebró la Misa, cantada por la Coral de músicos que tiene la Sixtina, unos 20 cantores de los mejores de Roma, situados en una tribuna, vestidos con sotanas moradas y roquetes, sin que hubiera instrumento alguno para acompañar el canto.

El Evangelio, se leyó en latín por el Predicador Apostólico el Padre Luis de Trento, capuchino, encargado de predicar la Cuaresma a Su Santidad. Hizo un corto sermón en latín, sobre el Evangelio del día. Concluida la Misa, el Papa dio la bendición y se retiró a sus habitaciones, a continuación la guardia suiza despejó la Sixtina. 
El autor nos recuerda que ha visto en varias ocasiones, a este Papa, besando el pie de la imagen de San Pedro, situada en la Basílica de San Pedro. Cuando sale del Vaticano, lo hace generalmente en un coche con cuatro grandes caballos negros y que detrás lleva siempre otro coche de respeto, con su correspondiente piquete de guardias nobles. La primera vez que lo vio el Papa, iba de paseo a Ponte-Mole, a unas dos millas de Roma, al lado del río. Para llegar allí, hay que pasar un gran puente, construido en 1805. El Papa iba acompañado de Monseñor Merode, Ministro que fue de la Guerra. Más adelante vio a los Reyes de Nápoles, que acuden con frecuencia a este paseo, uno de los puntos más retirados y bellos de Roma. En este paseo hay una casa a donde van los romanos a beber el famoso vino de Orbietto (sic), que es muy suave y claro.

Durante su recorrido por las diferentes Basílicas de Roma, recuerda la importancia del Jubileo universal que concede el Papa, establecido por el Papa Bonifacio VIII, en 1300, mandando que no se celebrase más que uno cada siglo. El Papa Sixto IV, dispuso que se celebrase cada 25 años, para que los cristianos pudiesen celebrarlo por lo menos una vez en su vida. En el siglo XIX, se han celebrado dos Jubileos, en 1825 con León XII y en 1846 con Pío IX.

En la Basílica de San Pedro, debajo del altar mayor, ha mandado hacer el Papa Pío IX, su sepultura, habiéndose labrado una rica Capilla subterránea, adornada de los más preciosos mármoles de todos los colores; en su centro se colocará una gran estatua de mármol blanco de este Papa, ya terminada.

Durante varios días se decidió a recorrer y conocer toda la ciudad. El día 16 de marzo, Viernes de Cuaresma, el Papa acompañado de toda su Corte civil, eclesiástica y militar, y de todo el Sacro Colegio de Cardenales, baja, como todos los viernes de Cuaresma, a hacer el Vía Crucis, y venerar el Sepulcro de San Pedro y las insignes reliquias que se conservan en la Basílica. Muchos visitantes, la mayoría extranjeros, acuden a ver de cerca al Sumo Pontífice, para presenciar este grandioso acto de su devoción, que tiene lugar a las 12,00 de la mañana. Al Papa y a los Cardenales se les reparten por los Maestros de ceremonias unos impresos en donde están las preces para ganar la indulgencia que $\mathrm{Su}$ Santidad tiene concedida, todos están de rodillas durante cada estación.

Por la tarde, de este Viernes de Cuaresma, el autor vio al Papa que entraba en el Palacio del Príncipe di Máximo, para asistir a una gran función religiosa que celebra el Príncipe en su Oratorio, anualmente en este día a su pariente San Felipe Neri, llamado el Apóstol de Roma, por el gran milagro que hizo este santo el 16 de marzo de 1583, resucitando a Pablo di' Máximo, hijo del Duque de Arzoli, uno de los antepasados de este Príncipe. La función fue muy solemne, asistiendo además los Reyes de Nápoles, y varios Príncipes romanos, los cuales tuvieron el honor de besar el pie a Su Santidad, que estaba sentado en un trono. 
El 19 de marzo, el autor fue al Vaticano, al despacho del Mayordomo de Su Santidad, para recoger la invitación para la Audiencia con el Papa. Por la tarde, fue a visitar al Embajador de España en la Sede, que era el Excmo. Sr. D. Javier de Istúriz y así conoció el Palacio de la Embajada Española.

El día 22 de marzo llueve intensamente en Roma, y nuestro viajero se queda en el Hotel, leyendo y recopilando información que transcribe en su libro. Relata cómo en aquella fecha, el Sacro Colegio de Cardenales, consta de 57 personas, de los cuales 6 son Obispos, 43 Presbíteros, y 8 Diáconos. De los Cardenales creados por Gregorio XVI, quedan 17, los demás han sido creados por Pío IX. El Cardenal más antiguo es Mario Mattei lo es desde hace 34 años. El más anciano era Antonio Tosti. El más joven, José Milesi-Pironi tiene 42 años. Desde 1614, tienen tratamiento de Eminencias.

Pío IX, ha creado 40 Cardenales. Durante su Pontificado han fallecido 66. Hay además tres Patriarcas de rito oriental: el de Antioquía de los melchitas, maronitas y sirios; el de Babilonia, de los caldeos y el de Cilicia, de los armenios; siete Patriarcas de rito latino: los de Constantinopla, Alejandría, Antioquía, Jerusalén, Venecia, Indias y Lisboa. La Santa Sede está representada ante las potencias extranjeras, por 7 Nuncios Apostólicos, residentes en Madrid, Bruselas, Lisboa, Munich, Nápoles, París y Viena. Hay 3 Internuncios en La Haya, Florencia y Módena y Río de Janeiro y un Encargado de Negocios en Lucerna. Además tiene 35 Consulados: Nueva York, Nueva Orleans, Río de Janeiro,Lima, Montevideo, Guatemala, Trieste, Venecia, Zara, Fiume, Roagusa, Amberes, Hamburgo, Nápoles, Palermo, Marsella y Argel, Burdeos, Bayona, Bastia, Niza, Gibraltar, Atenas, Confú, Malta, Amsterdam, Lisboa, Odesa, Génova, Cagliari, Barcelona, Cádiz, Málaga, Valencia, Estocolmo y Liorna.

Según las prácticas de la Corte Pontificia, el Papa y los Cardenales nunca salen a pie por las calles de Roma, ellos van en sus carruajes, como los Landós antiguos, pintados de encarnado, con dos grandes caballos negros. Cuando van de lujo, usan una carroza mucho mejor, con cochero y tres lacayos detrás de pie con sus libreas lujosísimas, y dentro del carruaje va el cardenal con su Gentilhombre de Cámara que es seglar, vestido todo de negro, con calzón corto y dos capellanes, de los cuales uno es su Secretario y el otro su Capellán de honor; además en estos casos los caballos van enjaezados de encarnado con preciosos adornos y guarniciones de charol negras con bronces dorados.

Este día, 22 de marzo, falleció el Cardenal Antonio Tosti, a los 74 años de edad y 34 de cardenalato. Su cadáver embalsamado ha estado tres días expuesto al público, según la costumbre romana.

Por la tarde, del día 23, a primera hora, visitó nuestro viajero la iglesia de San Luis de los franceses. El Papa Pío IX ha fundado aquí una Misa diaria, en sufragio por tantas víctimas de Francia. A continuación volvió a la Basílica de 
San Pedro, y allí se encontró con el Papa, que, con gran solemnidad, estaba haciendo el Vía Crucis. Detrás de su acompañamiento, iba la Reina viuda de Sajonia y su servidumbre.

A mitad de la tarde, después de visitar el jardín Botánico, regresó nuestro viajero al Vaticano para oír las Vísperas cantadas. Había muchos extranjeros. Cuando salía, se encontró con el Papa que, acompañado de Monseñor Merode, venía de paseo y recibió su bendición en la plaza del Vaticano.

El 24 de marzo, se celebraron los solemnes funerales, por el Cardenal Tosti, en la iglesia de Santa Cecilia, con asistencia del Papa, del Sacro Colegio y Prelados de Roma. La muerte de un Cardenal y la asistencia del Sumo Pontífice son un verdadero acontecimiento en la ciudad, no solo porque sucede a veces, después de muchos años, sino que también porque Su Santidad y los Cardenales, van de gran gala, y acude mucha gente para ver este espectáculo. El Papa lo hizo en un coche tirado por seis caballos negros, con guarniciones de charol y adornos de bronce dorado.

El funeral lo cantó el Cardenal Di Piettro, Camarlengo del Sacro Colegio. El Papa al acabar, rezó un responso ante el cadáver, que estaba sobre una gran cama imperial, vestido de casulla, con la sotana magna cardenalicia. El Papa fue vitoreado por las personas que estaban en la calle y de rodillas recibían su bendición.

El día 25, Domingo de Ramos, acude de rigurosa etiqueta, fue a la basílica de San Pedro, y ocupó un lugar distinguido, procurado por el Embajador español, y le tocó estar sentado al lado de un General mexicano y de un Caballero de la Orden de San Juan de Jerusalén. A las 9,00 horas, entró el Papa, sentado en la silla gestatoria, llevada a hombros por doce personas, vestidos de damasco y terciopelo encarnados, acompañado de todo el Sacro Colegio Cardenalicio y de más de treinta Patriarcas, Arzobispos y Obispos de ambos ritos; y llegada la comitiva desde la Capilla del Sacramento al centro del estrado, dejan el sillón en el centro y se levanta el Papa, que va revestido de capa magna y mitra y se sienta en su trono, ocupando cada cual su asiento. En la tribuna de los reyes, veíase a la Reina Viuda de Sajonia, al conde de Flandes, a la hija de María Cristina, casada con el príncipe Drago y otros, con su servidumbre, que se colocan de pie detrás de sus sillones.

En la tribuna diplomática, estaban los Embajadores de Francia, Austria, España, Portugal y otros, hasta unos diez, con sus secretarios detrás, todos de uniforme de gala. En cada tribuna hay un maestro de ceremonias, para la colocación de los asistentes.

En el centro del estrado se colocan en dos filas unos cincuenta guardias nobles de Su Santidad con los sables desenvainados. El resto de la iglesia está a disposición del público. A un lado hay una tribuna con celosías para los cantores. 
A una señal del Papa, comienza la ceremonia, con el acto de la obediencia de los cardenales: todos por su orden van a besar su mano que la tiene debajo de la cruz de la capa y luego los demás prelados, le besan el pie.

Prosigue la ceremonia, con la bendición de las palmas, con arreglo a ritual romano, las palmas no son grandes como las que se usan en las diócesis españolas, sino una tercera parte, de modo que se llevan en la mano como si fuese un ramillete de flores naturales, pero todas están muy adornadas con primorosos trabajos, obra y privilegio de una familia italiana. El Papa es quien distribuye las palmas, y quienes han sido elegidos, suben al trono, besan la mano del Pontífice si son Cardenales y el resto le besan el pie. El orden de los que recibieron las palmas, fueron: Cardenales, Patriarcas, Arzobispos, Obispos, Abades mitrados, Penitenciarios de esta Basílica, el Gobernador de Roma, el Príncipe romano asistente al trono, el Auditor de Rota, el Mayordomo, el Tesorero, los Proto-notarios apostólicos, los Generales de las ordenes, el Senador y Conservadores de Roma, el Maestro del santo Hospicio, los Prelados inferiores, los Mandatarios de los Cardenales, los Embajadores, los Generales y Jefes superiores del ejército francés.

Terminada la distribución de las palmas, sigue la ceremonia litúrgica, con la procesión y una vez finaliza, sigue con la Misa. Durante la lectura de la Pasión, el Papa se retiró al gabinete, que tiene detrás del solio. Dicha lectura, es cantada. Después que ha terminado, sale otra vez y sigue la Misa, y cuando ésta finaliza, da la bendición a todos los presentes y les concede treinta años de indulgencia. A las 13,00 horas, termina toda la ceremonia, el Papa es trasladado a la capilla de la Piedad, donde se quita los ornamentos y se retira al Vaticano, saliendo por la capilla del sacramento, que es donde está la escalera.

Por la tarde, el cardenal Gran Penitenciario va a la Basílica de San Juan de Letrán, en donde es recibido por el Colegio de penitenciarios y cuatro canónigos, y tomando una varita larga, se sienta en su gran confesionario, en donde oye las confesiones de todos los prelados, presbíteros y fieles que quieren, a los cuales les da después dos o tres golpecitos con la varita, en la cabeza, ganándose cien días de indulgencias por este acto de humildad que recuerda a los antiguos ritos de la penitencia pública.

Hoy ha terminado en Roma, la santa misión, que por disposición del Papa había comenzado el cuarto domingo de Cuaresma en diez principales Parroquias a la vez; un gentío inmenso ha acudido diariamente a oír la palabra divina y a practicar los piadosos ejercicios que el bondadoso Pío IX había dispuesto para el bien de las almas de sus súbditos: los resultados han sido muy satisfactorios, pues los romanos han sido dóciles a la palabra de los misioneros y han entregado los libros no permitidos y los periódicos que conservaban, los cuales fueron quemados en diferentes veces delante de las iglesias. Los vecinos del 
Trastevere y del cuartel de los montes, han entregado además varios puñales y pistolas, que han sido inutilizados públicamente.

El Lunes Santo, redirige por la tarde a las habitaciones del Papa, para ver uno de los muchos actos que demuestran lo que es el bondadoso Pío IX.:

«Su Santidad tiene dada orden de que a las cuatro de la tarde recibirá diariamente a todos los jefes, oficiales y soldados de la legión extrangera, que deseen tener el consuelo y la satisfacción de verle y hablarle y, en efecto, en el salón donde había de ser la audiencia, se pudieron en fila sobre unos treinta de dichas personas, arrodilladas y el Papa salió acompañado de dos prelados y fue hablando en francés a cada uno, concediendo indulgencias a quien se lo pedía, bendiciendo imágenes a otros, dando medallitas a otros, hasta que concluyó dirigiéndoles algunas palabras, luego les dio la bendición y se retiró. Este acto enterneció mucho a nuestro autor, viendo el cariño y bondad del Papa hacia sus fieles súbditos, y ver que cada tarde dedica un rato para estar con ellos».

El día 28 de marzo, Miércoles Santo, el autor, con una invitación, a las 7,00 de la mañana está en el Vaticano, vestido de etiqueta, va a la Capilla Sixtina, para asistir a la Misa. Apareció el Papa, acompañado de Monseñor Pacca, maestro de cámara de Su Santidad, de Monseñor Borromeo, mayordomo mayor, de ocho Arzobispos y Obispos, que eran camareros secretos y de un maestro jefe de ceremonias. La Misa la celebró el Papa y repartió la comunión a unas ciento veinte personas, entre ellas nuestro autor. El Papa, primero da su anillo a besar y luego le da la Comunión. Acabada de recibirla, cada comulgante, recibe de manos del Obispo Porfirio, Párroco del Vaticano, una cédula de cumplimiento pascual. Contiene un sello pontificio. Concluida la ceremonia, el Papa se quitó los ornamentos y pasó a su reclinatorio que estaba al lado del evangelio con objeto de dar gracias, y luego otro de sus prelados, salió para decir otra Misa, que oyó el Papa y también los presentes. Cuando terminó esta otra Misa, ya eran las 10,00 de la mañana y al salir de la Capilla, recibieron el recado de que pasaran a las habitaciones de monseñor Borromeo a desayunar. Les dieron chocolate, café y sorbetes, todo servido con profusión y mucha educación. Los honores los hizo en nombre del Papa, Monseñor Pacca, su maestro de cámara, Monseñor Borromeo, su mayordomo mayor y otros elevados prelados. Los laicos presentes, dieron las gracias a Su Santidad por conducto de dichos prelados.

Por la tarde, el Sumo Pontífice, en la Capilla Sixtina, ofició vestido de capa y mitra, el canto del Benedictus y Miserere.

El día 29, Jueves Santo, fue nuestro viajero, a las 8 de la mañana, a la Capilla Sixtina, donde estaba el Papa y todo el Sacro Colegio, para asistir a los Oficios de este día. En la tribuna de reyes, están los Reyes de Nápoles Francisco II y su joven esposa; la Reina viuda de Sajonia; los Grandes Duques Coburgo-Gotha y el hermano de la Emperatriz de Méjico, con sus servidumbres y en sus respectivos asientos todos los Embajadores con sus secretarios a

Hispania Sacra, LIX

120, julio-diciembre 2007, 595-612, ISSN: 0018-215-X 
la izquierda y las Señoras a la derecha con sus riquísimos trajes negros y preciosos aderezos.

En el altar de la Capilla, se coloca en este día el magnífico paño de tapicería de Clemente VIII, que representa la muerte de Cristo; el trono del Papa está forrado de alamar de plata y Su Santidad lleva una capa magna y mitra de oro. Primero se efectúa el acto de la obediencia de los cardenales, comenzando luego la Misa que celebra un Cardenal, según el ceremonial ordinario de este día, cuando llega la Consagración, salen de la sacristía doce clérigos de la cámara con hachas encendidas. Concluida la Misa, se arregla la procesión para llevar el sacramento al Monumento, que está dispuesto en la Capilla Paulina, que está en el mismo gran salón que la Sixtina y fue hecha por Paulo III.

«Dispuesta ya la procesión, desciende el Papa de su trono y recibe el Sagrado Cáliz, con las especies sacramentales, el cual es llevado por Su Santidad que va a pie debajo del palio, al llegar a la capilla Paulina, se deposita en la urna el cáliz con el ceremonial ordinario, y cerrada, se entrega la llave al cardenal Gran Penitenciario, que es el que ha de celebrar al día siguiente».

A continuación vino el acto de la bendición Urbi et Orbi. El balcón, donde se sitúa el Papa, estaba adornado de lujosas colgaduras, y de un gran dosel de terciopelo carmesí. En un lugar destacado, en la tribuna para personas invitadas, estaba nuestro autor.

«El Papa salió, con la Tiara, que le había regalado la reina de España, sobre la silla gestatoria, y se hizo un profundo silencio. La voz del Papa, de un hermoso timbre y llena de vida, se oía desde todos los puntos de la vasta Plaza del Vaticano y al dar la bendición, puesto de pie y dirigiendo su mirada y sus manos al cielo, como si recibiera del Altísimo la divina gracia en aquel supremo momento, fue un espectáculo imposible de explicar, pues es lo más sublime y sobrenatural que la imaginación puede alcanzar, es un acto de agradables y hondas emociones al considerar al Vicario de Cristo en la tierra, en el ejercicio de uno de sus actos más sorprendentes, implorando el perdón hasta para sus más encarnecidos enemigos. Al concluir la bendición, el castillo de San Angelo, principió a disparar cañonazos, las campanas a tocar y la inmensa muchedumbre a vitorear calurosamente al Papa, quien tuvo la atención de hacer algunos momentos de detención en el balcón para demostrar su correspondencia a los afectos de los fieles, viéndosele sumamente conmovido y con las lágrimas en los ojos y levantándose por segunda vez nos bendijo nuevamente».

A continuación, se lee desde el mismo balcón, en latín y en italiano la indulgencia plenaria que Su Santidad concede a todos los presentes, lo cual hacen dos Cardenales diáconos, arrojando al pueblo los dos papeles.

Después, en el crucero de la inmensa iglesia de San Pedro, tuvo lugar el lavatorio de los pies, que realiza el Papa. Las personas que son propuestas para este objeto al Papa son trece, se les llama Apóstoles y en esta ocasión eran: el 
Embajador de España, uno; el Embajador de Francia, uno; el Embajador de Austria, uno; el Embajador de Portugal, uno; el Cardenal Secretario de Estado, uno; el Cardenal Camarlengo, uno; el Cardenal de la Propaganda, dos; el Cardenal de los armenios, uno; el Capitán de la guardia suiza, uno; el Mayordomo de Su Santidad, tres. Estos apóstoles van vestidos con una túnica y un gorro de lana blanca.

Una vez que ha llegado el Papa con los Cardenales, Prelados y demás acompañantes, se sienta en su Solio, se canta el Evangelio del día y se quita la capa, quedándose con la mitra de plata, estola y un gremial o gran lienzo ceñido a manera de un delantal, y precedido de dos maceros, maestros de ceremonial y dos Cardenales, se arrodilla delante de cada apóstol y les lava el pie derecho que ponen dentro de una gran vasija de planta; el tesorero del Sacropalacio, va detrás, dando a cada uno un ramo de flores naturales y dos medallas conmemorativas: una de oro y la otra de plata. Concluido el acto, se dicen las oraciones de costumbre y el Papa desciende de su trono y se sube a sus habitaciones.

Posteriormente el Sumo Pontífice, da la comida a los Apóstoles. La mesa se encuentra situada en un grandísimo salón que hay en la fachada principal de la misma Basílica de San Pedro, en el cual se forman tribunas para las personas reales, cuerpo diplomático, señoras y demás personas que tienen invitación. La mesa está encima de una gran tarima con el fin de que todos puedan ver bien la comida, la mesa está decorada con muchas flores, es estrecha y larga. Se sientan los Apóstoles a un lado enfrente de los invitados y Su Santidad en una esquina, de lado a la gente; en la mesa, en el lugar donde se sienta el Papa, está escrito con pétalos de flores el nombre de Pío IX. Entra el Papa, vestido normalmente, y bendice la mesa y comienza a recibir los platos de la sopa, que le presentaban los Cardenales, Patriarcas, etc..de rodillas; concluidos estos, se sacaron y se sirvieron por el Papa una porción de principios y en los postres el Papa se retiró, siendo ovacionado en el momento de abandonar el comedor. Durante la comida, un camarero secreto leyó un libro piadoso.

Entonces, los invitados, se acercaron a la mesa para poder contemplar de cerca todo lo que había en ella, y recibían objetos de los Apóstoles, una flor, una medallita, etc...

A las 14,30 horas, terminó este acto y con ello las funciones de la mañana.

Nuestro viajero, cuando abandonó el lugar, salió a la Plaza, que estaba repleta de carruajes.

Por la tarde, van en procesión a la Basílica de San Pedro, numerosas Cofradías, para recibir la bendición de las reliquias de la Santa Faz, la Vera-Cruz y la Santa Lanza. 
El día 30, Viernes Santo, en la Capilla Sixtina se celebra los Oficios del día, con asistencia del Papa y Cardenales, vestidos con ropa morada obscura y el Papa sólo es asistido por un Prelado. El Papa concede una indulgencia de 30 años a los asistentes. En la Adoración de la Santa Cruz, comienza primero el Papa, que realiza las tres genuflexiones, sin mitra y sin capa, y después de adorarla, deposita en una bolsa de damasco que hay al lado, cien escudos de oro; luego pasan los Cardenales, que van de dos en dos, sin calzado, depositando cada uno en la bandeja de plata, un escudo de oro, después pasan también descalzos, los demás Prelados y Generales de las Ordenes, y continúan los Oficios. En la Capilla Sixtina, queda expuesto el Lignum-Crucis, que el Patriarca de Jerusalén, envió a Roma, en tiempo del Papa San León el Grande, que está dentro de un cristal de roca, adornado con piedras preciosas.

El día 31, Sábado Santo, en la Capilla Sixtina, se celebran los oficios del día, según el ritual ordinario, con asistencia del Papa y de los Cardenales. Se canta la Misa del Papa Marcelo, obra del Maestro Palestrina, llamada así porque este Papa derogó la prohibición que había dado acerca de la música en la Capilla Sixtina al oír tan grave y sublime Misa, y para la cual, el Papa se reviste de ornamentos blancos y los Cardenales se quitan los hábitos morados y se ponen la púrpura cardenalicia.

Comenzada la Misa, que celebra un Cardenal, el Papa recibe la Obediencia de todo el Sacro Colegio. Al Gloria in excelsis Deo, todos los guardias levantan sus armas, se descubre el cuadro del Altar, las campanas tocan y el castillo de San Angelo hace los disparos de Ordenanza. Concluida la Epístola, un Auditor de la Rota, con dos Maestros de ceremonias, llega a los pies del Trono y dice a Su Santidad: «Pater Sancte, annuntio Vobis gaudium magnum, quod est, Alleluya». , le besa el pie y se retira. La Misa continua como siempre y al final el Pontífice da la bendición a los presentes, y posteriormente se retira.

Por la tarde, el autor fue recibido por el Papa. Recibió una carta del Maestro de Cámara del Pontífice, en la que decía:

«El Santo Padre se ha dignado recibir en Audiencia al Ilustrísimo Señor Francisco Ximénez, el Sábado 31, á las cuatro y media de la tarde», y además se añadía que «se ha de presentar con el billete, de uniforme o frac negro y corbata blanca» y que «está prohibido pedir alguna gracia al Papa por la cual haya este de escribir en el acto de la Audiencia».

A la hora prevista, ya estaba de uniforme en las Galerías de Rafael, sitio elegido para la Audiencia, y donde estaba el Trono Pontificio, y algunos criados de Palacio, a la Audiencia asistieron varios Caballeros y Señoras francesas. No se hizo esperar mucho Pío IX, que junto el Maestro de Cámara y el Mayordomo Mayor, se presentó con sotana blanca de estar en casa. Todos los invitados se arrodillaron en fila ante el trono y el Papa fue uno por uno haciéndoles pregun- 
tas en francés; más al llegar al autor, que le saludó diciéndole que era español, le dirigió la palabra en este mismo idioma, y le preguntó «si era marino», pues el autor llevaba puesto el uniforme de San Juan de Jerusalén, y llevaba bordadas varias áncoras y el Papa, no le permitió que le besara el pie y sí el anillo. Cuando el Papa hubo hablado con todos y cada uno de los invitados, se pudo de pie y al ver que los invitados seguían de rodillas, les hizo levantarse y les dirigió en francés las siguientes palabras

«Hijos míos, hoy que celebra nuestra Santa Madre la Iglesia el gran misterio de la Resurrección de Jesucristo, el primer misterio de nuestra fe, base de nuestra Religión Católica, voy á dirigiros una palabra sobre Él antes de bendeciros. Efectivamente, queridos hijos míos, la resurrección del Hijo de Dios es el fundamento de nuestra santa creencia; y aquel que no crea en este misterio, no puede llamarse católico, pero el que crea en él, Nolite timere, que no tema á nadie, pues la gracia Divina descenderá sobre él, socorriendo á unos en sus necesidades, consolando á otros en sus aflicciones, confundiendo á los enemigos de los otros, y así sucesivamente...Padres y Madres de familia que me oís, creed y enseñad á vuestros hijos este gran misterio; y si así lo hacéis, Nolite timere, no temáis contratiempos en vuestras casas, pues vuestros hijos, con tan religiosa educación, serán vuestro consuelo y felicidad, siendo útiles á ellos mismos y al Estado; no temáis á vuestros mas encarnizados enemigos, pues el Ángel del Señor, que vela por vosotros, los exterminará, librándoos de ellos; no temáis mas que al Ser Supremo, á fin de no abusar de sus inmensas bondades para con nosotros; ....y en prenda segura de ello, Yo en su nombre os bendigo, á fin de que buenos y sanos lleguéis á vuestras familias: os bendigo, y recibid esta bendición para vosotros y vuestras familias, deseándoos á todos la gracia del Padre, del Hijo y del Espíritu Santo».

A dichas palabras, añadió algunas reflexiones, que impresionaron a los oyentes. Después les concedió un montón de indulgencias, y les bendijo los rosarios, medallas, crucifijos y otros objetos piadosos que llevaban.

Aquí el autor, reflexiona para sí mismo y comenta en su libro:

«Este imponente acto forma época en la historia de la vida del afortunado mortal que ha podido ver realizado su afán de ir á Roma y hablar personalmente con Pío IX. Y si esto es así efectivamente, ¿¿con cuanta mayor razón la formará y mucho más gloriosa para mí, que he tenido además el raro privilegio y envidiable honor de recibir la Sagrada Hostia de sus santas manos; de obtener de su puño y letra Indulgencia Plenaria para la hora de la muerte, para mí y mi familia; de que se haya servido Su Santidad concederme licencia para leer y retener en mi poder libros prohibidos sin limitación alguna; y por último, de que me haya honrado con el distinguido título de Notario Apostólico de la Curia Romana, honor que no se suele dar á extranjeros, tanto que no hay ninguno en Valencia, ni quizás en España».

«En las recepciones, el Papa manifiesta una benevolencia especial: se dice con justicia que en estos casos su mirada penetra hasta el corazón del que le escucha, depositando en él, una chispa consoladora de su hermosa alma, recibiendo á todos con una bondad y ternura grandes, llamándoles hijos, hablándoles con una amable sonrisa y concediéndoles con gusto las gracias que desean. Todo cuanto he dicho es inferior a la realidad, por más

Hispania Sacra, LIX

120, julio-diciembre 2007, 595-612, ISSN: 0018-215-X 
que haya quien me tache de exagerado en mi descripción. Cuando se ve y habla a Pío IX, siente uno cierta felicidad que no se puede expresar con palabras; y cuando uno sale de su augusta presencia, siente en sí una alegría y una calma interior que dura mucho tiempo. Sin duda alguna Pío IX es mas grande de lo que se pueda ponderar; es el más generoso de todos los Príncipes; es el más piadoso de todos los Pontífices; y es, en fin, el Monumento de Roma más digno de ser admirado».

El día 1 de abril, Primer Domingo de Pascua, el autor fue a la Basílica de San Pedro, las calles estaban llenas de carruajes y de gente. Dentro de la iglesia, está la Guardia Palatina, los Granaderos y los Suizos, para dejar libre el camino para el Papa. En la Tribuna Real, estaban los Reyes de Nápoles; la Reina viuda de Sajonia; los Grandes Duques de Sajonia-Coburgo-Gotha; el Conde de Flandes, el hermano de la Emperatriz de Méjico, con sus servidumbres. En la Tribuna del Cuerpo Diplomático, estaban todos los Embajadores y Secretarios.

Antes de las diez de la mañana, apareció el Sumo Pontífice, en la silla gestatoria, con la tiara puesta y todo el acompañamiento que dictaba el protocolo. El Papa baja por la escalera Real al Pórtico y entra por la puerta del centro. El Papa tiene tres tiaras, una que le regaló Napoleón I, al Papa Pío VII, después de su destierro; otra regalada a Pío IX por la Guardia Palatina y la última, que es la mejor, que le regaló Doña Isabel II, Reina de España, la cual está valorada en 80.000 duros y tiene muchos brillantes, zafiros, perlas, esmeraldas y otras piedras preciosas, siendo muy notable el diamante que forma el mundo y la cruz de brillantes del remate. Antiguamente la Tiara Pontificia sólo tenía una corona de oro, hasta que el Papa Bonifacio VIII, en el año 1300, añadió la segunda corona y en 1334, Benedicto XII, añadió la tercera corona de oro.

A su entrada, los cornetas de la Guardia Noble tocan dentro de la iglesia y los cantores entonan el motete «Tu es Petrus».

La procesión se componían de las siguientes personas: «Un maestro de ceremonias, los Procuradores del Colegio; los Predicadores Apostólicos; los Confesores de la Familia Apostólicos; los Procuradores Generales de las Ordenes religiosas; el Guarda-joyas del Sacro Palacio; un capellán llevando una Tiara, acompañado de dos Suizos; los capellanes, que llevan las mitras Pontificales; dos Hujieres Pontificios; los Ayudantes de Cámara; Capellanes de Su Santidad; Camareros secretos; los Abogados Consistoriales; los Camareros de honor; los Cantores de la Capilla; los Abreviadores; los Votantes de la Signatura; los Clérigos de la Cámara; los Auditores de Rota; el Maestro del Sacro-Palacio; dos Camareros secretos, con dos mitras; el Maestro del Santo Hospicio; los Camareros de Capa y Espada; el Auditor de la Rota que lleva la Cruz Papal; dos Acólitos Pontificios con el incensario y naveta y siete más llevando candeleros con luces, que representan los siete candeleros del Apocalipsis, los siete dones del Espíritu Santo y las siete Basílicas de Roma; dos Porteros; el Subdiácono latino en medio del Diácono y Subdiácono griegos; los Penitenciarios de San Pedro; los 
Abades Mitrados; los Obispos; los Patriarcas y Arzobispos Latinos, Griegos, Búlgaros, Armenios y demás Orientales; los Cardenales Diáconos, Presbíteros y Obispos; el Senador y Conservadores de Roma; el Gobernador de Roma; el Príncipe Romano asistentes al Sacro Solio; el Aposentador Mayor; el Caballerizo Mayor; los dos primeros Maestros de Ceremonias; el Cardenal Subdiácono; el Cardenal Diácono; el Cardenal Asistente á la Misa; el Jefe de los Suizos; el Estado Mayor de los Guardias Nobles; el General de las tropas Pontificias, con sus Ayudantes; varios Hujieres y Maceros y el Pontífice en la silla gestatoria bajo Palio y dos Camareros secretos que van a los lados con grandes abanicos de preciosas plumas largas de colores, con el mango forrado de terciopelo encarnado, con adornos dorados; detrás va la Guardia Suiza, el Decano y Auditores de la Rota con los Proto-Notarios Apostólicos.

Sobre el Altar Mayor Papal están en este día dos preciosas estatuas de san Pedro y san Pablo, la grandiosa Cruz y hermosos candeleros de plata y oro, obra de mucho mérito, del célebre Cellini; también se coloca una tiara y cuatro mitras, sobre pies forrados de terciopelo encarnado, por los cinco Patriarcados que el Pontífice domina. En este Altar no puede celebrar mas que Su Santidad y los Cardenales autorizados por un Breve especial... Así siguió relatando nuestro insigne escritor, sus días en Roma. 